\title{
Research and Planning Design of Traditional Village Tourism Pension Model-Taking Madiping Village in Longnan as an example
}

\author{
Zhiwei Yang $^{1 *}$, Yuan Wang ${ }^{1}$, Yingchang Xiang ${ }^{1}$ \\ ${ }^{1}$ CCTEG Chongqing Engineering (GROUP) Co., Ltd., Chongqing, 400010, China
}

\begin{abstract}
The tourism pension in traditional villages is based on the rural agricultural production value and tourism cultural value as the attraction, relying on the natural landscape, human customs, historical buildings and other resources of traditional villages. With Madiping village as an example, through the surrounding economic factors, climate environment, comfort, leisure, entertainment, medical rehabilitation, spirit culture and service facilities of these seven factors questionnaire survey analysis, hierarchical structure model is established by using Analytic Hierarchy Process (AHP), it is concluded that the present stage tourism endowment patterns relations, weights of factors affecting peasant casual is the trend of the development of local tourism endowment. On the basis of qualitative research, based on the protection of the historical features of traditional villages, the principle of rural tourism, leisure and old-age care was created, and the planning and design of remote tourism and old-age care was carried out in combination with rural resources and environment, so as to achieve the purpose and significance of promoting rural economic revitalization and regional development.
\end{abstract}

\section{Introduction}

In the 21 st century, the global ageing population problem is becoming increasingly obvious. By the end of 2018, according to the statistics, the total number of people aged 60 and above in China reached 249 million, accounting for $17 \%$ of the total population, and 166 million people aged 65 and above, accounting for $11.9 \%$ of the total population. China's elderly population is expected to account for $35.1 \%$ of the total population around 2050, which means that China will enter a country with severe aging problem [1]. According to the statistics of Gansu Province Population Statistics Bureau at the end of 2018, the elderly aged 60 and over 65 accounted for $14.99 \%$ and $9.83 \%$ of the total population of Gansu Province. Faced with such a severe situation on how to deal with the problem of aging population in the next few years or decades, the society should actively advocate the use of new ideas and new methods to solve it. China's traditional villages are numerous, widely distributed with excellent natural environment. After thousands of years of development, they have rich material and intangible cultural heritages, and have high ecological and cultural value. However, due to the factors of location, transportation and industrial foundation, some traditional villages are developing slowly and even facing the danger of disappearing [2]. Combining the protection and inheritance of traditional villages with the pension industry is not only an innovation, but also a positive sustainable development strategy. In addition, the warm-hearted and honest customs of rural culture, the communication principle of "keeping watch and helping each other" among the neighbors, as well as the leisure and spacious courtyard life in the countryside have become the yearning of most elderly people. Therefore, the development of pension industry in traditional villages has unique advantages.

\section{Overview of Madi Village}

Madiping Village is located in the Minshan Mountain System of Qinghai Tibet Plateau and Longnan area of Gansu Province, where the branch of West Qinling Mountain extends. It has beautiful mountains and rivers, and is filled with cultures. It is a multi-ethnic community inhabited by Han, Tibetan, Qiang and Hui Nationalities. Its architectural types are diverse, and many traditional villages with historical culture are preserved. Madiping Village is the most representative traditional village in Longnan area. It has primitive thatched buildings and folk culture. It has rich tourism resources, beautiful environment and pleasant climate. It has great attraction to the foreign tourism elderly population. Madiping Village, located in the important place of Guanting town and Lianghekou Township, is closed to the national highway G212, with convenient transportation. The forest covers the whole village, with a forest coverage rate of more than $90 \%$ and negative oxygen ions of $12000 / \mathrm{cm}^{3}$. The climate is mild in four seasons. The average temperature in spring, summer and autumn is $24^{\circ} \mathrm{C}$, the

\footnotetext{
"Corresponding author's e-mail: tempiotto@yeah.net
} 
precipitation is $475 \mathrm{~mm}$, the sunshine time is more than 2100 hours, and the altitude is $1470 \mathrm{~m}$. Madiping Village is located in the ancient Qiang Tibetan inhabited area. Dangchang state was established in the first year of Yongjia in the Western Jin Dynasty, which has a history of more than 2000 years. Madiping Village is on the edge of development in the process of development. The loss of population is serious. Some historic buildings have been demolished and the facilities and environment are backward. According to the survey and statistics, at present, the annual tourism volume of Madiping Village is about 300000 persons times, with profound tourism cultural value, which has laid a solid foundation for the construction of a new rural pension mode.

As a village located in the hinterland of ancient Qiang and Tibetan, Madiping Village has great potential to develop into a tourism industry for the aged with its unique geographical location and architectural style.

\section{Research on Tourism Pension Model of Madiping Village Based on AHP}

\subsection{AHP overview}

When facing the problems of economic, social, planning and many other fields, people are faced with a complex system consisting of interrelated and interrelated factors, which need to be compared, judged, evaluated and finally made decision. In 1970s, American T.L.saaty and others put forward the Analytic Hierarchy Process (AHP), which is a comprehensive, operational, scientific, systematic, qualitative and quantitative analysis method combined with [3]. In architectural design, due to the influence of subjectivity and multiple factors, architectural styles show diversity. This method can be used for systematic evaluation of non structural characteristics and multiconcept, multi-factor, and multi-criteria. The Analytic Hierarchy Process $(A H P)$ is to select the better from the crowd scheme and provide strategy research for the planning of architectural scheme.

\subsection{Basic steps of AHP}

\subsubsection{Establishing AHP structure model}

In the domestic and foreign literature research and tourism pension development projects, there are more than 20 development models of tourism pension in different places. Among them, ChangPeng combines tourism industry with pension real estate industry and puts forward the development mode of migrant, family, convalescent, diversified and rural leisure tourism pension real estate[4]; Based on the research of tourism pension real estate projects and related literature at the present stage, Zheng Xiaoyun puts forward five types: embedded, private plots, scenic resort and recuperation, farmhouse entertainment and remote interaction[5]; Kong Jinping proposed that the types of pension in different places can be divided into tourism type, visiting relatives and friends type, migratory birds settling down type, remote pension type and remote exploration type pension mode[6]. According to the geographical location and tourism resources of Madiping village, it is a better choice to develop vacation recuperation type, remote replacement type, farmhouse leisure type and three-dimensional health preservation type. It is also the mainstream tourism pension mode at home and abroad and forms the corresponding industrial system. Vacation recuperation type is a tourism pension mode that combines hotel industry, tourism industry and recuperation industry[7]; It refers to the mode of interactive replacement of the residential right of the elderly in different cities [8]; The rural leisure type is a new rural tourism pension mode which combines tourism, leisure, sightseeing, rural life experience and pension community[9]; Based on the concept of health preservation, the three-dimensional health care model is a comprehensive pension model integrating sports, religion, tourism, medical and other health services [10]. The purpose of the evaluation of the pension problem is to establish a complete evaluation system and evaluate the pension scheme reasonably and effectively. According to the analytic hierarchy process, the evaluation index system for elderly care issues is composed of three levels: target level (O), criterion level (C), and plan level (P), and the selection of indicators should be based on systematic, hierarchical, representative, and operable Principles of sex and quantification. According to the structural model in Figure 1, the measurement indicators for each element are determined on a comprehensive and objective basis. A number of university professors and experts provide systematic guidance and suggestions on the factors in the evaluation indicator system, and select the optimal tourism pension model as The target level, the vacation and recuperation type, the remote replacement type, the farming leisure type, and the three-dimensional health type in each plan level are based on the economic factors, climate environment, comfort, leisure and entertainment, medical rehabilitation, spiritual culture and service facilities of the standard level. Perform weight comparison and analysis, get the weight relationship between the scheme layer and the target layer, and build a hierarchical structure model of the evaluation system.

\subsubsection{Construction of AHP weight index system}

According to the index evaluation system of the structural hierarchy model constructed in Figure 1, 200 questionnaires were conducted among retired elderly people and industry experts in Lanzhou, Xi'an and other big cities. The importance of factors at the same level was compared and scored with 1-9 points. Use the mathematical software MATLAB to calculate the maximum eigenvalue and eigenvector of the paired comparison matrix on the collected scoring statistics table. And check the consistency of the judgment matrix. If the consistency ratio $\boldsymbol{C R}=\boldsymbol{C I} / \boldsymbol{R} \boldsymbol{I}<\mathbf{0 . 1}$, the matrix is considered to pass the consistency test, otherwise it is retested. $\boldsymbol{C I}=\mathbf{0}$ means complete consistency. According to the analysis of 187 valid questionnaires, the specific statistical results are shown in table 1-6. 


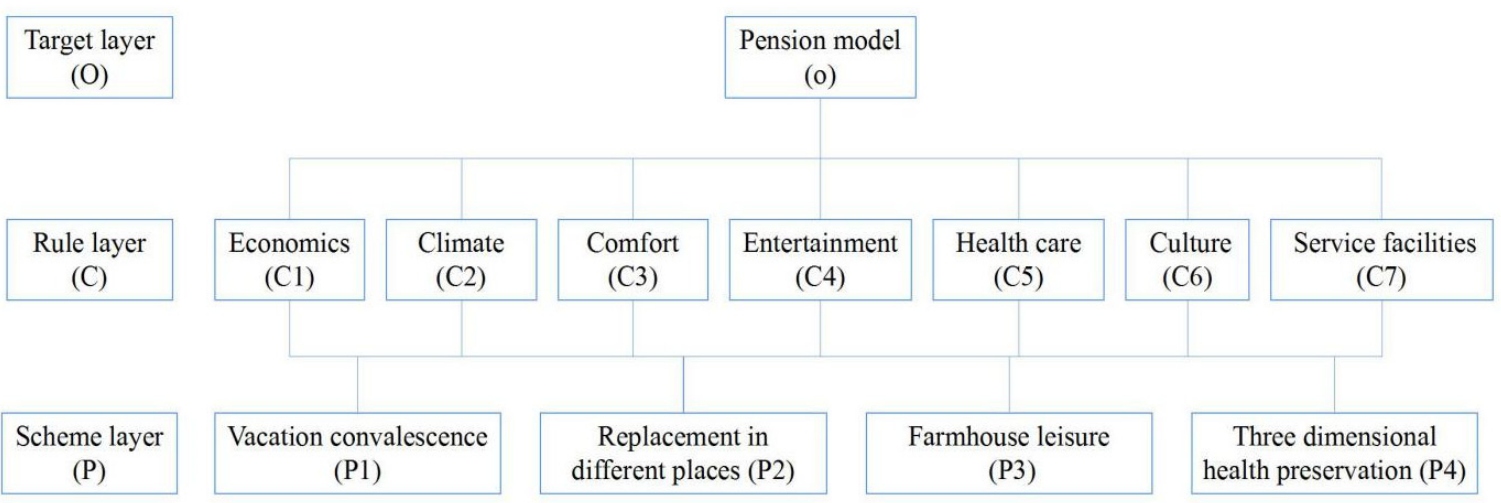

Figure 1. Tourism pension model hierarchical structure model.

Table 1. Judgment matrix of pension mode $(\mathrm{O})$ and criterion layer $(\mathrm{C})$

\begin{tabular}{cccccccc}
\hline $\mathrm{O}$ & $\mathrm{C} 1$ & $\mathrm{C} 2$ & $\mathrm{C} 3$ & $\mathrm{C} 4$ & $\mathrm{C} 5$ & $\mathrm{C} 6$ & $\mathrm{C} 7$ \\
\hline $\mathrm{C} 1$ & 1.0000 & 5.0000 & 8.0000 & 0.3333 & 8.0000 & 3.0000 & 2.0000 \\
$\mathrm{C} 2$ & 0.2000 & 1.0000 & 3.0000 & 0.3333 & 0.5000 & 0.5000 & 0.2000 \\
$\mathrm{C} 3$ & 0.1250 & 0.3333 & 1.0000 & 0.2000 & 0.5000 & 0.5000 & 0.3333 \\
$\mathrm{C} 4$ & 3.0000 & 3.0000 & 5.0000 & 1.0000 & 4.0000 & 3.0000 & 2.5000 \\
$\mathrm{C} 5$ & 0.1250 & 2.0000 & 2.0000 & 0.2500 & 1.0000 & 1.3333 & 0.5000 \\
$\mathrm{C} 6$ & 0.3333 & 2.0000 & 2.0000 & 0.3333 & 0.7500 & 1.0000 & 0.6667 \\
$\mathrm{C} 7$ & 0.5000 & 5.0000 & 3.0000 & 0.4000 & 2.0000 & 1.5000 & 1.0000 \\
\hline
\end{tabular}

Table 2.Judgment matrix of economic factors (C1), climate environment (C2) and scheme layer (P)

\begin{tabular}{cccccccccc}
\hline C1 & P1 & P2 & P3 & P4 & C2 & P1 & P2 & P3 & P4 \\
\hline P1 & 1.0000 & 0.2500 & 0.1250 & 0.3333 & P1 & 1.0000 & 0.2000 & 0.1667 & 0.3333 \\
P2 & 4.0000 & 1.0000 & 0.2500 & 3.0000 & P2 & 5.0000 & 1.0000 & 0.3333 & 4.0000 \\
P3 & 8.0000 & 4.0000 & 1.0000 & 6.0000 & P3 & 6.0000 & 3.0000 & 1.0000 & 6.0000 \\
P4 & 3.0000 & 0.3333 & 0.1667 & 1.0000 & P4 & 3.0000 & 0.2500 & 0.1667 & 1.0000 \\
\hline
\end{tabular}

Table 3.Judgment matrix of comfort $(\mathrm{C} 3)$, recreation $(\mathrm{C} 4)$ and scheme layer $(\mathrm{P})$

\begin{tabular}{cccccccccc}
\hline C3 & P1 & P2 & P3 & P4 & C4 & P1 & P2 & P3 & P4 \\
\hline P1 & 1.0000 & 0.3333 & 0.1429 & 0.5000 & P1 & 1.0000 & 0.5000 & 4.0000 & 5.0000 \\
P2 & 3.0000 & 1.0000 & 0.3333 & 2.5000 & P2 & 2.0000 & 1.0000 & 8.0000 & 6.0000 \\
P3 & 7.0000 & 3.0000 & 1.0000 & 7.0000 & P3 & 0.2500 & 0.1250 & 1.0000 & 3.0000 \\
P4 & 2.0000 & 0.4000 & 0.1429 & 1.0000 & P4 & 0.2000 & 0.1667 & 0.3333 & 1.0000 \\
\hline
\end{tabular}

Table 4.Judgment matrix of medical rehabilitation (C5), spiritual culture (C6) and program layer (P)

\begin{tabular}{cccccccccc}
\hline C5 & P1 & P2 & P3 & P4 & C6 & P1 & P2 & P3 & P4 \\
\hline P1 & 1.0000 & 0.2500 & 0.1250 & 0.5000 & P1 & 1.0000 & 3.0000 & 8.0000 & 6.0000 \\
P2 & 4.0000 & 1.0000 & 0.3333 & 4.0000 & P2 & 0.3333 & 1.0000 & 5.0000 & 4.0000 \\
P3 & 8.0000 & 3.0000 & 1.0000 & 6.0000 & P3 & 0.1250 & 0.2000 & 1.0000 & 0.6000 \\
P4 & 2.0000 & 0.2500 & 0.1667 & 1.0000 & P4 & 0.1667 & 0.2500 & 1.6667 & 1.0000 \\
\hline
\end{tabular}

Table 5.Judgment matrix of service facility (C7) and solution layer (P)

\begin{tabular}{ccccc}
\hline C7 & P1 & P2 & P3 & P4 \\
\hline P1 & 1.0000 & 0.2500 & 0.2000 & 0.5000 \\
P2 & 4.0000 & 1.0000 & 2.0000 & 4.0000 \\
P3 & 5.0000 & 0.5000 & 1.0000 & 6.0000 \\
P4 & 2.0000 & 0.2500 & 0.1667 & 1.0000 \\
\hline
\end{tabular}




\subsubsection{Calculate the weight vector and consistency check of single-level sort}

Use the mathematical software MATLAB to arrange and combine the paired comparison matrices, and use the functions $[\boldsymbol{x}, \boldsymbol{y}]=\operatorname{eig}(\boldsymbol{A})$ and $\boldsymbol{m}=\operatorname{diag}(\boldsymbol{y})$ to find the maximum eigenvalue $\lambda_{\max }$ and the normalized eigenvector $\boldsymbol{\omega}_{\boldsymbol{i}}$ corresponding to the eigenvalue. The maximum eigenvalue of pairwise comparison matrix in Table 1 is $\lambda$ $=7.5597$, and the corresponding normalized eigenvector $\omega=(0.2799,0.0585,0.0375,0.3219,0.0747,0.0830$, 0.1445). Since $C I=0.0933, R I=1.32, C r=0.0707<0.1$, indicating that the matrix in Table 1 has passed the consistency test. In other words, the weight vector of the total hierarchical ranking of the matrices in Tables 2, 3, 4 and 5 is calculated and the consistency test is conducted. According to the $\boldsymbol{C R}_{\boldsymbol{k}}$ in Table 6, if the consistency ratio is less than 0.1 , the consistency test is passed.

Table 6. Scheme layer hierarchical ordering and normalized feature vector

\begin{tabular}{cccccccc}
\hline $\boldsymbol{k}$ & 1 & 2 & 3 & 4 & 5 & 6 & 7 \\
\hline $\boldsymbol{\omega}_{\boldsymbol{k} \boldsymbol{}}$ & 0.0535 & 0.0572 & 0.0693 & 0.2995 & 0.0599 & 0.5853 & 0.0741 \\
$\boldsymbol{\omega}_{\boldsymbol{k} 2}$ & 0.2196 & 0.2774 & 0.2187 & 0.5370 & 0.2604 & 0.2707 & 0.4511 \\
$\boldsymbol{\omega}_{\boldsymbol{k} 3}$ & 0.6198 & 0.5612 & 0.6094 & 0.1060 & 0.5879 & 0.0583 & 0.3741 \\
$\boldsymbol{\omega}_{\boldsymbol{k} 4}$ & 0.1071 & 0.1042 & 0.1026 & 0.0575 & 0.0918 & 0.0857 & 0.1007 \\
$\boldsymbol{\lambda}_{\boldsymbol{k}}$ & 4.1140 & 4.2097 & 4.0510 & 4.1899 & 4.0813 & 4.0635 & 4.2097 \\
$\boldsymbol{C I}_{\boldsymbol{k}}$ & 0.0480 & 0.0699 & 0.0170 & 0.0633 & 0.0271 & 0.0212 & 0.0699 \\
$\boldsymbol{R}_{\boldsymbol{k}}$ & 0.9000 & 0.9000 & 0.9000 & 0.9000 & 0.9000 & 0.9000 & 0.9000 \\
$\boldsymbol{C}_{\boldsymbol{k}}$ & 0.0533 & 0.0777 & 0.0189 & 0.0703 & 0.0301 & 0.0236 & 0.0777 \\
\hline
\end{tabular}

\subsubsection{Calculate the total ranking weight and consistency test of the hierarchy}

To determine the ranking weight of the relative importance of the scheme level to the target level, it needs to be carried out from the highest level to the lowest level. The obtained ranking results are shown in Table 7 . The weight vector of the scheme level to the total objective is $(0.1811,0.3659,0.3661,0.0870)$, and because $C R=0.0524$ $<0.1$, the total ranking of the levels has passed the consistency test.

Table 7. Pension model and evaluation factor weight value

\begin{tabular}{cccccccc}
\hline Pension mode & $\begin{array}{c}\text { P1 Vacation convalescent } \\
\text { type) }\end{array}$ & $\begin{array}{c}\text { P2 (Displacement } \\
\text { type) }\end{array}$ & $\begin{array}{c}\text { P3 } \\
\text { (Rural leisure } \\
\text { type) }\end{array}$ & $\begin{array}{c}\text { P4 (Three dimensional health } \\
\text { preservation type) }\end{array}$ \\
\hline Weight value & \multicolumn{2}{c}{0.1811} & \multicolumn{2}{c}{0.3659} & 0.3661 & 0.0870 \\
\hline $\begin{array}{c}\text { Evaluation } \\
\text { factors }\end{array}$ & $\mathrm{C} 1$ & $\mathrm{C} 2$ & $\mathrm{C} 3$ & $\mathrm{C} 4$ & $\mathrm{C} 5$ & $\mathrm{C} 6$ & $\mathrm{C} 7$ \\
\hline Weight value & 0.2799 & 0.0585 & 0.0375 & 0.3219 & 0.0747 & 0.0830 & 0.1445 \\
\hline
\end{tabular}

\subsection{Study on the tourism pension mode of Madiping Village}

From the investigation and analysis of Lanzhou and Xi'an around Madiping village and the guidance and evaluation of many industry experts, the ranking results of each level and the general level are obtained. Among the evaluation factors, $\boldsymbol{C} 4>C \mathbf{C}>\boldsymbol{C} 7>\boldsymbol{C 6}>\boldsymbol{C 5}>\boldsymbol{C 2}>\boldsymbol{C}$ 3, the weight of leisure and entertainment is relatively largest, followed by economic factors, and the requirements for facilities and comfort are general. Therefore, the elderly pay more attention to leisure and entertainment, which reflects the old people's idea of "happiness for the aged", followed by economic factors and other problems. In the tourism pension mode, $\boldsymbol{P 3}>\boldsymbol{P} \mathbf{2}>\boldsymbol{P} \mathbf{1}>\boldsymbol{P} 4$, the rural leisure pension has the largest impact factor, followed by the replacement type, the three-dimensional health care type is the lowest, the independent courtyard and simple in the rural leisure community Communication environment and close experience of the countryside's fireworks atmosphere are rare resources of the city. The excellent natural environment, low rent land resources and superior traditional tourism cultural value of Madiping village are the important guarantee to attract foreign tourism endowment resources. With the improvement of living standards in China, the key problem of developing tourism pension market is to reduce the pension cost, and the key to solve this problem is to combine rural leisure tourism pension with new rural construction. 


\section{Planning and Design of Madiping Village Tourism Community for the Aged}

\subsection{Historical and cultural features of Madiping traditional villages}

Madiping Village is located in the center of Lianghekou Township and Guanting Town, closed to 212 national highway, with convenient transportation. In addition, between Madiping Village and the surrounding villages, there is a transportation line of historical and traditional Qiang road - mule team, which is also one of the current

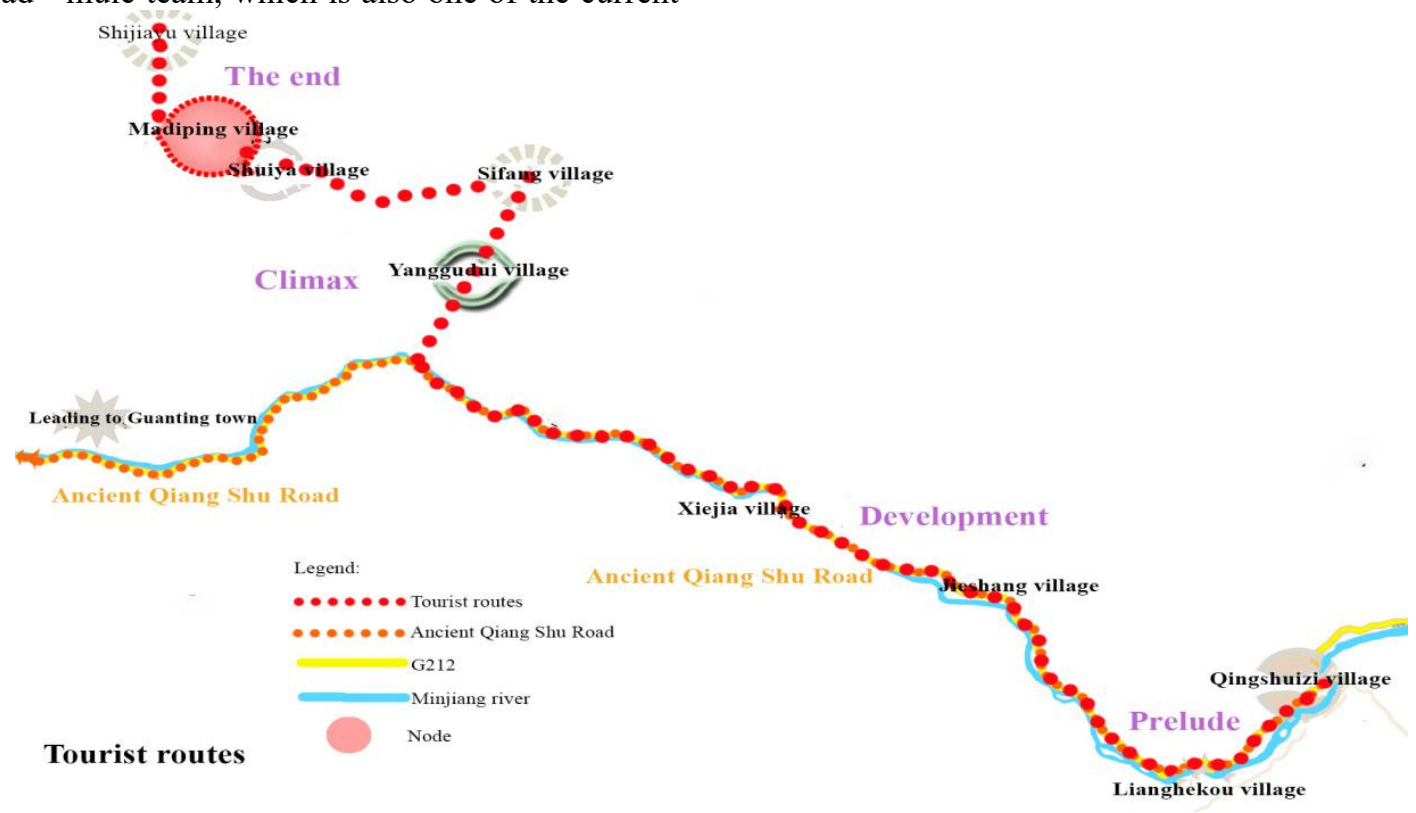

Figure 2. Madiping Village Tourism Road Map. characteristics of tourism culture. The architectural forms of Zhaizi village and qingshuizi village close to Qiang road tend to be official style. In the path of connecting villages into a system, Madiping Village presents a unique style. Taking qingshuizi village yanggudui village Sifang village Kemen Road Village shuiya village Madiping Village shijiayu village as the tourism route, the characteristic nodes and tourism nodes are planned with Prelude (starting point), development (buffer point), climax (explosion point) and ending (rest point) according to the film design mode, and finally combined with the scheme design, which reflects the important position of Madiping village in the tourism route (Figure. 2) .

\subsubsection{Form layout}

Madiping Village at the foot of Baicao mountain forms three major settlements according to different clans and surnames, which are connected by roads. Different settlements are affected by topography and traffic, but in the overall spatial layout, they all show the form of retreating step by step according to the mountain potential. Madiping Village crosses Baicao mountain to the north for shijiayu village and ancient horse farm. Together with shuiya village, yanggudui village and kemendao village in the south, madiping village has built a situation of wartime guarding and post-war farming. It has always been the important task of guarding the ancient Qiang and Shu Road in the South and guarding the military garrison in the north, which has high military defense value [11]. The style buildings of the settlement are mainly watchtowers and thatched roof buildings, which are distributed on the half slope ground, and have rich morphological relations.

\subsubsection{Architectural features}

Madiping Village was the hinterland of Dangchang in ancient times. Most of the buildings were surrounded by high-rise buildings surrounded by stone and soil. Light wells were mined in the middle. The bottom layer was livestock pen, and the top floor was occupied by people. With small high windows, the indoor light was very dark. It is similar to the Qiang Tibetan Architecture in Hehuang valley. Now, it is verified that the construction mode of the combination of Diqiang and Tibetan from Hehuang Valley is quite different from the surrounding quadrangle settlements [12]. Madiping village is mainly composed of Qiang Zang Fort building and thatched roof building. The walls are stacked with earth and stone, and the structure adopts bucket type to stabilize the shape. The unique architectural style is also an important part of Madiping village's historical and traditional style (Figure. 3). 


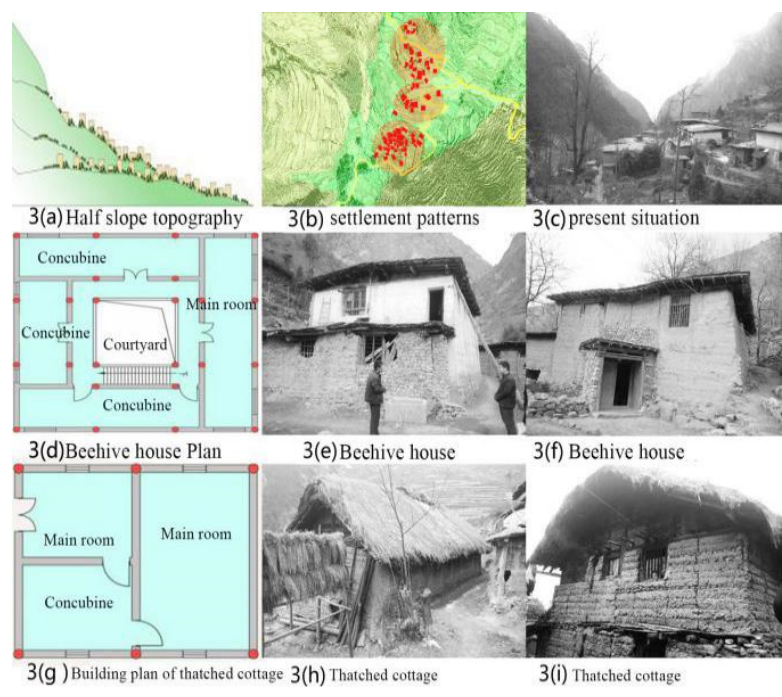

Figure 3. Current situation and traditional folk house of the village of Madiping.

\subsubsection{Traditional history and culture of Madiping Village}

Madiping village is composed of Ran, yuan and Li tribes of the 16 ethnic groups of "Mujia" in Tibet and Qiang. Madiping village people in the mountains and forests have retained and inherited most of the Qiang customs and inherited the 561 year chieftain culture. Madiping village is mainly engaged in agriculture, and the traditional handicrafts include embroidery, cross stitch and knitting. During festivals, weddings and funerals, sacrifices, gatherings or hospitality, it is necessary to have wine and food. For weddings, it is necessary to eat "cooking wine", for banquet guests, "drinking", and for Chongyang Festival, it is necessary to have nine bowls for banquets. The songs and dances include love songs, wine songs, folk songs, ritual songs and Xiong Meng dance, Sarang dance, yo coarse cloth and kesigsi. When encountering happy events and festivals, they will beat drums and dance. There are 10 kinds of drum beats, such as "Zhenshan drum" and "wedding drum". The most solemn festivals are the "mountain sacrifice meeting" in spring and autumn and the "Qiang calendar Festival" on October 1 of the lunar calendar.

\subsection{Planning and design of Madiping Village tourism community for the aged}

\subsubsection{Design objectives and principles}

This project is based on the service radius, scale and grade of Madiping Village and the target group. Based on the sustainable development of traditional villages, the development of five-star scale is mainly based on the service radius of Madiping Village which can be controlled within 3 hours' drive, such as Lanzhou City and Xi'an city; the target group is retired elderly people with economic foundation in big cities. In principle, the design

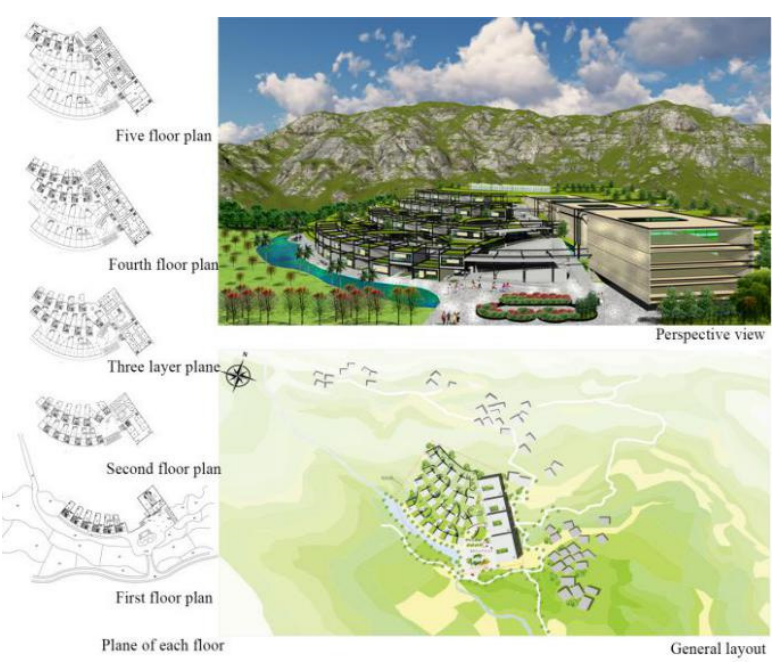

Figure 4. Rendering, general layout and plan of Madiping village tourism aged community.

follows the principles of people-oriented, local conditions, safety and comfort, and carries out rural tourism and leisure activities according to the regional natural environment; maintains the historical features of traditional villages and promotes the harmonious unity of human and nature; creates a comfortable space environment for the elderly based on the elderly; inherits the folk culture of traditional villages to enrich the elderly's pension life; architectural design Pay attention to the needs of the elderly and meet the barrier free requirements.

\subsubsection{Design mode}

The main group of the industry is the retired people who live regularly or irregularly and have good physiological function. According to the AHP method, the best tourism pension suitable for Madiping Village is the rural leisure type, which relies on the rural cultural landscape, rural cultural life and the simple mutual aid principle among the neighbors to carry out the migrant type and Sightseeing Leisure type tourism pension. Based on the unique communication environment and residential concept of Madiping Village, a tourism elderly community is proposed in the abandoned site in the southwest corner of Madiping Village (Figure. 4). In terms of function, it is divided into two parts: the eastern part is the comprehensive office service area for health care, with a total of five floors, including convalescence and rehabilitation, fitness and entertainment, shopping, office, catering and other multi-functional service areas, such as chess and card room, shared kitchen, etc., for life experience; in the west, there are 23 rental courtyard houses and 5 public activity centers, which perform folk songs and dances with villagers for activity experience The two sides of the path and the roof of the building are designed as planting farms, and rent-free farmland is provided for mutual plowing and vegetable planting with local villagers, which promotes the combination of foreign advanced ideas and farming experience for planting 
experience, and enriches the elderly's pension life (Figure.

$5)$.
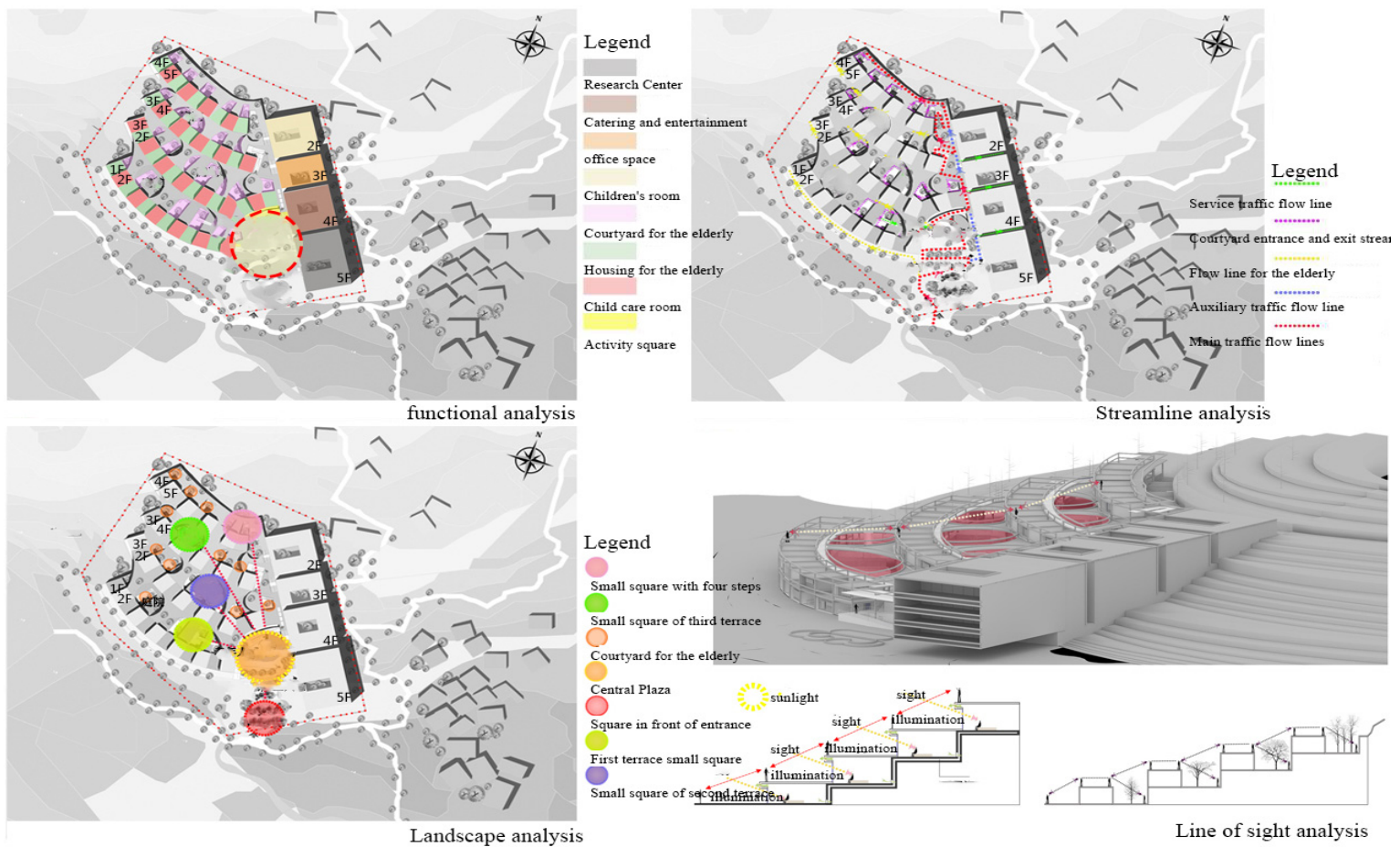

Line of sight analysis

Figure 5. Function, streamline, landscape, line of sight and technical analysis of Madiping village tourism aged community.

In the evolution of the historical development of traditional villages, it is not a simple development and protection mode. Based on the current situation of the region, it is necessary to excavate the history and culture, so as to produce interactive and vital buildings, which make the "rural space" mutation. The evolution process of traditional villages is the reflection on the current situation and the response of the times. The development of tourism pension in traditional villages is not only the support of rural industry, but also the continuation of the village. The residential concept of rural residence is to introduce the feelings of scenery and ancient connotation into the architectural design, and the flowing shared rest space brings the possibility of communication, mutual viewing and sharing happiness for the elderly. The concept of functional space comes from the layout of "beehive" and "thatched house" in Madiping Village. The two units are connected by shared space, and the internal and external space is connected by the middle shared space. In terms of spatial relations, it has broken and broken ties and achieved unity on the whole. Using the terrain elevation difference transformation, the excessive relationship of space is extended, and the extended platform space is used to promote the communication between the elderly. Through the treatment of space combination and conception relationship, the courtyard is dug out on the same level layer, which makes the courtyard hidden in the building (i.e. sunken courtyard). However, the residence of the elderly is closely linked with the courtyard, forming a contrast between the real and the virtual, increasing the excessive relationship of gray space. Combined with the unique situation of height difference between the upper and lower families in ancient villages, stairs are arranged in the courtyard to enrich the upper and lower families The connection of the elderly, the same, space processing to achieve the elderly independent private space and shared space, to meet the spiritual needs of the elderly. The south facing slope space of the building provides the elderly with sunshine and simple planting space. The unit courtyard building shape and space are integrated into the inclusiveness and openness of local buildings in Madiping village, which makes the tourism pension community hidden in the countryside (Figure 6). 


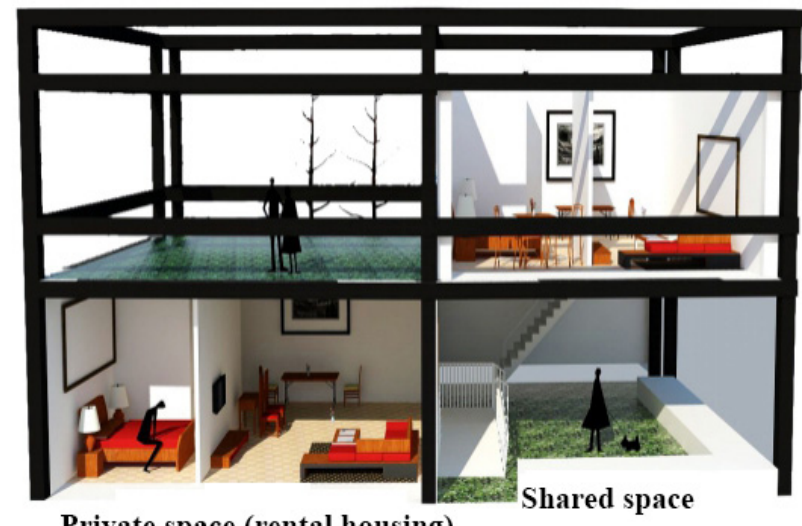

Private space (rental housing)

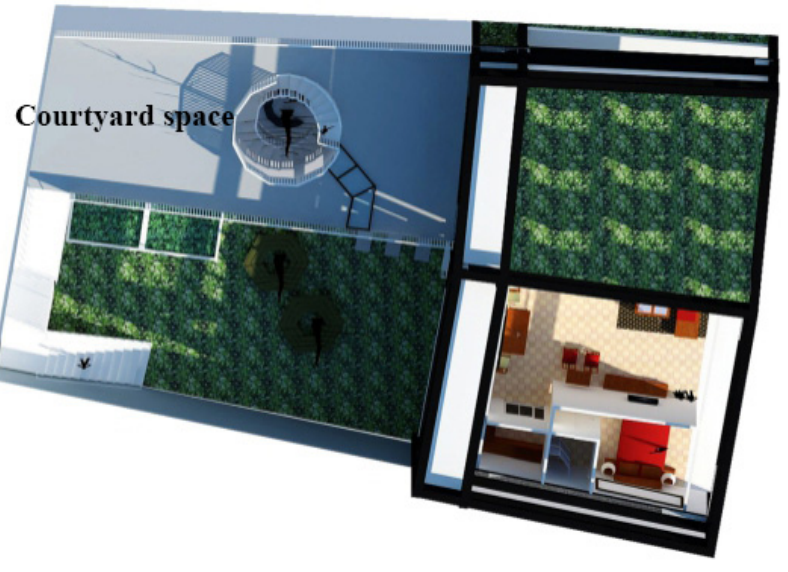

Figure 6. Unit space combination of Madiping village tourism aged community.

\subsubsection{Management model}

The traditional village tourism pension industry is invested by the government, the implementation of the government led publicity, property management companies, the development of online booking rental housing app software. Combined with the whole area tourism route map of Longnan City, the node parts are created to provide dynamic support for the tourism pension industry. With the improvement of people's living standards, the traditional village tourism pension in the era of Internet of things is facing great development opportunities, which is also the inevitable trend of smart pension. Using information technology, Internet and Internet of things technology, we can form online and offline "rental pension housing" reservation mode, create an efficient and efficient service system for the elderly, form a service industry-oriented management mode, activate the tourism frequency of traditional villages, and make tourism elderly groups get spiritual satisfaction of happiness and dependence [13].

\subsubsection{Protection and development mode}

The development of tourism pension industry in traditional villages provides economic conditions for the sustainable development of traditional villages. In terms of the systematic relationship of planning and architecture, the tourism elderly community is organized according to the road texture, building relationship and activity site of Madiping village. The pedestrian flow route of the elderly community refers to the village entrance path. The construction mode of "beehive" and "thatched cottage" is extracted from the architectural form and spatial relationship. The historical folk grain drying field is incorporated into the elderly community to form a landscape square It retains the authenticity of traditional villages. At present, the service ratio of nursing staff in the domestic pension industry is $10: 1$, which is far from the international standard of $2: 1$. We should improve the service system, train local villagers to develop the pension industry, and at the same time, the living environment for the elderly should meet the standards of tourist attractions, attract foreign tourism elderly groups, increase the income of local residents, and the Qiang Tibetan buildings left in Madiping village can be transformed into reception tours B \& B for guests. The protection of traditional villages should not only rely on the government, but should promote the development of tourism and increase the economic income of villagers. In this way, local villagers can spontaneously protect historical buildings, maintain the living environment of villages, and the villages can also retain people.

\section{Summary}

In the face of the aging age and the development of traditional villages, based on the qualitative research of analytic hierarchy process, the author combines the remote tourism pension industry with the protection and sustainable development of Madiping village, and provides the elderly with a safe, comfortable and pleasant living environment for the elderly based on the peopleoriented, local conditions and harmonious unity of man and nature.

First, in terms of planning and design, the traditional living environment of Madiping village has been incorporated into the elderly community. According to the design of village style, the construction mode of community buildings and the spatial relationship of places show the division of static and dynamic buildings for the elderly to meet the spiritual needs of the elderly. The south facing slope provides the elderly with simple planting and enjoying sunlight conditions, just like "old people have their own yard", and the elderly life scene of falling leaves and returning to roots.

Second, in terms of architectural design concept, the courtyard buildings in the community extract the architectural functions and construction technology elements of Madiping village, so as to retain the flavor of the countryside, arrange them into an overall space system in the mode of unit splicing, and pay attention to the structural texture of the original buildings.

Third, the protection and development of historical villages rely on digging their own value, exploring the historical heritage of villages, continuing the value and context of ancient villages, so as to realize the protection 
and sustainable development of historical buildings, and fundamentally solve the development problems of ancient villages. The protection and sustainable development of Madiping traditional village should be carried out by the mode of government leading, owner participation, social support and enterprise operation, so as to strengthen the publicity of the village. Traditional village tourism pension industry promotes the development of rural economy, alleviates the problem of urban pension and revives rural vitality.

\section{Acknowledgments}

The work described in this paper was fully supported by a grant from the Major State Basic Research Development the National Natural Science Foundation of China (No.51668039).

\section{References}

1. Hao Fuqing, Wang Tanling, Bao Wenhan. Strategic thinking and policy orientation of actively coping with population aging $[\mathrm{J}]$. Macroeconomic management,2019(02):43-47+61.

2. Liao Junhua. Protection and development of traditional villages from the perspective of Rural Revitalization [J]. Reform, 2018 (04): 130-139.

3. Zhou, R.H. (2014) Consider urban road network structure optimization of logistics and distribution. Geospatial Information, 12(03): 54-55+6.

4. Chang Peng. Discussion on the development mode of tourism pension real estate in China [J]. National business information (Theoretical Research), 2014 (01): 73 .

5. Zheng Xiaoyun, Han Lina. Development mode selection of tourism pension real estate based on fuzzy comprehensive evaluation[J]. Shanxi architecture, 2017,43 (02): 222-224.

6. Kong Jinping, Liu Yuwen. Exploration of the diversification of pension modes: interactive remote pension [J]. Journal of Hunan University of science and technology, 2008 (01): 73-75.

7. Thomas Vittori.Analyzing the use of history in mathematics education: issues and challenges around Balacheff's $\mathrm{cK} \phi$ model[J]. Educational Studies in Mathematics,2018,99(2).

8. Zhang Jing, Sun Chang. Research on interactive tourism pension mode in different areas $[\mathrm{J}]$. Tourism overview (second half of the month), 2019 (01): $77+$ 80 .

9. Chitra B,Ramaswamy R S,Suba V.Toxicity Evaluation of Pũrṇa Cantirotaya Centũram,a Siddha Medicine in Wistar Rats.[J]. International scholarly research notices,2015,2015.

10. Wang Shuyu: Health real estate is a threedimensional system [J]. Real estate guide, 2012 (08): 63.
11. Liu Guanghua. Some issues on the history of Zhouqu [J]. Social science review, 2018,33 (01): 78-82.

12. Zhou Song. On the origin and development of Dangchang Qiang [J]. JOURNAL OF NORTHWEST UNIVERSITY FOR NATIONALITIES (PHILOSOPHY AND SOCIAL SCIENCES), 2004 (01): 42-48.

13. Zhang Bo, Han Junjiang. Internet plus Research on wisdom and health care for the aged [J]. macroeconomics management, 2018 (12): 40-44. 